\title{
Influência do fator de forma do agregado graúdo no desempenho mecânico e hidráulico do concreto permeável
}

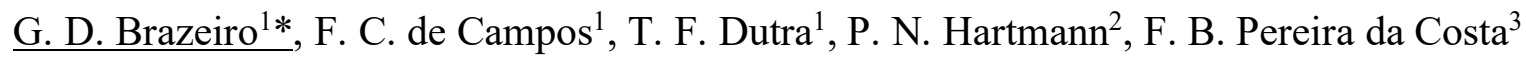 \\ *Autor de contato: gabrielbrazeiro.aluno@unipampa.edu.br \\ ${ }^{1}$ Graduando em Engenharia Civil, Universidade Federal do Pampa, Alegrete, Brasil \\ ${ }^{2}$ Mestranda em Engenharia, Universidade Federal do Pampa, Alegrete, Brasil \\ ${ }^{3}$ Professora do Curso de Engenharia Civil e do Programa de Pós-Graduação em Engenharia - PPEng, Universidade \\ Federal do Pampa, Alegrete, Brasil
}

\begin{abstract}
RESUMO
O concreto permeável, classificado como um concreto macroporoso, possui elevada capacidade drenante. Entretanto, por ser um material relativamente novo, ainda carece de estudos e normas para sua produção e aplicação. Neste contexto, este trabalho objetiva avaliar as propriedades mecânicas e hidráulicas do concreto permeável, sob a influência do fator de forma dos agregados. Realizou-se a caracterização de três agregados com diferentes índices de forma, que foram moldados de acordo com um traço padrão e uma mesma curva granulométrica. Foram realizados ensaios de potencial hidráulico e resistência mecânica. A variação do índice de forma, em lamelar, lamelar-alongado e cúbica-lamelar não exerceu expressiva influência nas propriedades hidráulicas e mecânicas, todavia os processos de britagem do agregado revelaram alteração nas propriedades mecânicas.
\end{abstract}

Palavras chaves: pavimento permeável, permeabilidade, propriedades mecânicas, conectividade dos poros, material sustentável.

\section{INTRODUÇÃO}

Países como Japão, Estados Unidos e países europeus buscam maneiras de lidar com o escoamento superficial, sendo uma das soluções encontradas a utilização de pavimentos permeáveis, entre eles o concreto permeável. No Brasil o uso desse tipo pavimentação não é muito difundido, o que reflete em um cenário corriqueiro de enchentes e inundações em cidades de grande e médio porte devido sobretudo a gestão ineficiente do escoamento das águas da chuva. Apesar de não ser difundido há um número crescente de pesquisas sobre o uso concreto permeável sua aplicabilidade como pavimento drenante, como por exemplo, o uso desse material como pavimentos leves em estacionamentos, vias de tráfego leve e áreas de lazer, como proposto por Valença (2021).

O concreto permeável, muitas vezes conhecido como concreto poroso, é um tipo concreto utilizado em pavimentos e tem a função de aumentar a permeabilidade à água. O que o difere do concreto convencional é uma alteração no traço, já que o concreto permeável dispõe de pequenas proporções de agregado graúdo e nenhuma ou uma pequena quantidade de agregado miúdo. Além disso, o concreto permeável costuma ter uma distribuição granulométrica uniforme ao invés de bem 
graduada. O concreto permeável é produzido eliminando todo ou maior parte dos finos na mistura, permitindo a passagem da água pelos vazios interconectados da matriz endurecida, ou seja, tem a habilidade de transportar grandes volumes de água através da estrutura do material.

A permeabilidade deste material o torna eficaz para lidar com uma série de importantes questões ambientais como: reabastecimento das águas subterrâneas; redução do escoamento superficial de águas pluviais; redução do fenômeno da ilha de calor; filtragem da água que percola através dele; facilidade da arborização (permite ao ar e a água chegar às raízes); e evita acúmulo de água. Segundo a Environmental Protection Agency (EPA, 1997) a utilização de pavimentos de concreto permeável permite uma infiltração de até $80 \%$ do volume de escoamento anual, e pode filtrar até $65 \%$ de partículas que não são dissolvidas e até $95 \%$ dos sedimentos no escoamento. Uma revisão das características sustentáveis do material e a comparação sistemática com os métodos de pavimentação convencionais foi abordado por Singh (2020), onde também é discutido a manutenção do concreto permeável e a mitigação de efeitos prejudiciais a cidade.

A avaliação da qualidade de um concreto permeável está diretamente relacionada às características da estrutura porosa. A porosidade e a morfologia (forma) dos agregados determinam o tamanho e distribuição dos poros, bem como a conexão entre os mesmos. Entretanto, não é só a quantidade e tamanho dos poros que define a permeabilidade do material, mas também o fator de conectividade entre os vazios que permita uma boa percolação. A permeabilidade é a característica de desempenho mais importante de concretos permeáveis e, como acontece com qualquer material poroso, as propriedades de transporte são inerentemente dependentes das características da estrutura dos poros. No entanto, tem sido comum relacionar a permeabilidade do concreto permeável à sua porosidade, principalmente devido à facilidade com que a porosidade pode ser medida em um material macroporoso.

A morfologia do agregado graúdo é uma das suas principais características já que a forma que ele assume determina muitas vezes seu comportamento na matriz cimentícia. Esse agregado pode assumir formas cúbicas, lamelares, alongadas e discoides, e ainda intermediárias entre essas. Silva (2018) comprova que agregados com formato mais cúbico apresentam valores de resistência à compressão mais elevados do que os agregados de forma lamelar, porém o fator de forma pode influenciar outras propriedades mecânicas e hidráulicas do concreto.

$\mathrm{O}$ fator de forma de um agregado é determinado por dois fatores predominantes, sendo eles o tipo de rocha mãe a ser britado e o tipo de britagem a que a rocha é submetida (Gonçalves et al, 2007 apud Arnold, 2011). As categorias de britagem podem ser impacto, atrito ou compressão e influenciam nessas características dos agregados, já que a quebra das rochas em frações menores pode resultar em pedaços cúbicos, lamelares ou até mais esféricos. Os tipos de britadores podem ainda resultar em agregados mais cúbicos como é o caso do britador de atrito ou mais lamelares como é o caso dos britadores de impacto. A britagem por impacto pode resultar em microfissuras no agregado, afetando a resistência final do mesmo (Boaretto, 2017).

Nesse sentido, esta pesquisa tem como objetivo avaliar a influência morfológica do agregado nas propriedades hidráulicas (porosidade e permeabilidade) e mecânicas (resistência à compressão axial e resistência à tração na flexão), além do desgaste por abrasão, em uma mistura de concreto permeável de traço padrão e para uma mesma curva granulométrica.

\section{PROCEDIMENTO}

Este trabalho foi dividido em duas etapas. Na primeira etapa, realizou-se os ensaios de caracterização dos materiais e, também, confeccionou-se equipamentos para serem utilizados posteriormente na segunda etapa, a qual envolveu as moldagens e os ensaios.

\subsection{Etapa 1}


Com o intuito de avaliar a influência do fator de forma dos agregados graúdos no concreto permeável, utilizou-se três britas de origem basáltica provindas de diferentes jazidas, sendo ambas caracterizadas como brita 0 (zero). Para a caracterização, necessitou-se realizar, de acordo com as normas, os ensaios de absorção, massa específica, granulometria e fator de forma.

Para o ensaio do fator de forma, realizado conforme a NBR 7809 (ABNT ,2019), encontrou-se valores de 1,96, 2,64 e 3,57. Entretanto, a norma não faz referência à nomenclatura do índice de forma, logo, para complementar essa caracterização, baseou-se no trabalho de Silva e Geyer (2018) classificando os agregados como cúbica-lamelar (ACL), lamelar (AL) e lamelar-alongada (ALA), respectivamente, estes apresentados na Figura 1.

A diferença do índice de forma dos agregados decorre do processo de britagem. O ACL foi obtido por um britador de impacto, o qual objetiva gerar agregados de formato cúbico, neste sistema de britagem os agregados passaram por três britadores distintos, sendo eles um britador de mandíbula, seguido por um do tipo cônico e enfim o britador de impacto. Obteve-se o ALA a partir de uma britagem secundária, sendo utilizado um britador de mandíbula seguido por um britador do tipo cônico. O britador cônico, esmaga a rocha até obter a granulometria desejada e normalmente gera agregados de formato lamelar. Quanto ao agregado AL, não foi possível obter informações acerca do seu processo de britagem. (Figueira et al., 2010).

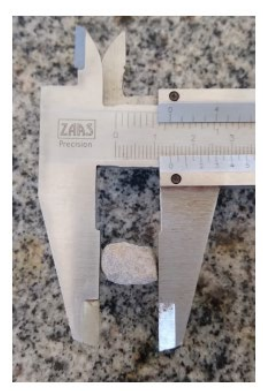

ACL

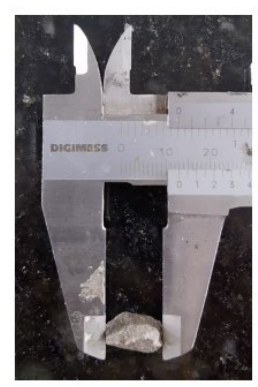

AL

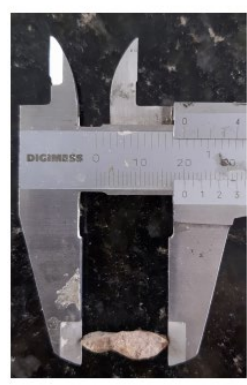

ALA

Figura 1. Índice de forma dos agregados utilizados.

Os ensaios de absorção e de massa específica foram realizados conforme a norma NBR NM 53 (ABNT, 2005). Obteve-se os valores de massa específica do agregado na condição saturado superfície seca para os diferentes índices de forma, e com isso, realizou-se uma média aritmética dos dados, que foi utilizada no traço padrão da mistura de concreto permeável.

A granulometria foi determinada de acordo com a NBR NM 248 (ABNT, 2003). Através dos resultados, observou-se que os agregados possuíam granulometrias distintas, embora dentro dos limites estabelecidos pela norma. Para eliminar a variável granulométrica, os agregados foram peneirados e separados por número da abertura de peneira, assim foi possível construir uma curva granulométrica ótima entre os limites pré-estabelecidos por norma. A curva ótima se manteve constante para todos os agregados, conforme mostra a Figura 2. Ressalta-se que os materiais passantes na peneira 4,75 $\mathrm{mm}$ foram descartados para os três agregados estudados, devido à baixa disponibilidade do agregado ALA nesta faixa granulométrica. 


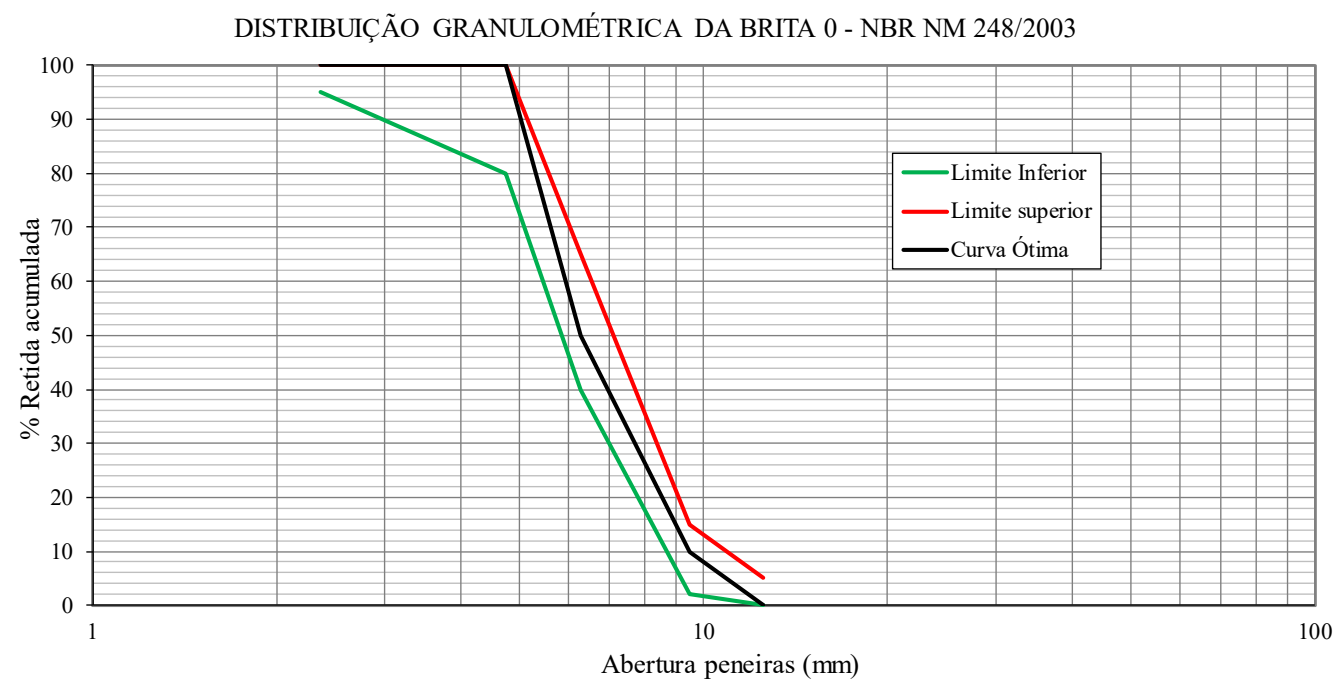

Figura 2. Curva granulométrica ótima utilizada no traço padrão de concreto permeável.

Ainda na primeira etapa, realizou-se a confecção de um rolo, que tem como finalidade, simular a compactação real de um pavimento/calçada de concreto permeável. O rolo tem massa de $50 \mathrm{~kg}$, sendo constituído de concreto convencional, como mostrado na Figura 3 (b).

Para medir a permeabilidade dos corpos de prova do concreto permeável, necessitou-se a execução de um permeâmetro de carga variável, utilizando materiais convencionais como canos e conexões de PVC, como pode ser visto na Figura 3 (a).
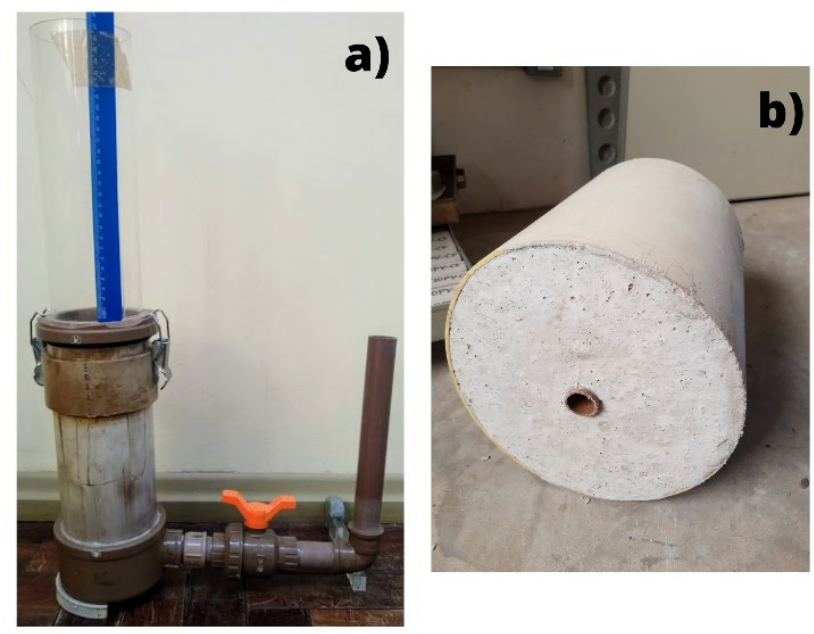

Figura 3. Equipamentos confeccionados na etapa 1, a) Permeâmetro, b) Rolo para compactação.

\subsection{Etapa 2}

A etapa 2 compreendeu a moldagem dos corpos de prova (CP's) e a realização de ensaios mecânicos e hidráulicos. $O$ traço utilizado nesse trabalho é embasado na metodologia desenvolvida por Pereira da Costa (2019) e leva em consideração a massa específica do agregado graúdo, neste caso a média dos três agregados, como citado anteriormente, uma relação água/cimento de 0,26, uma porosidade projetada de $25 \%$ para um traço de 1:4 (cimento:agregado). O cimento utilizado nesta pesquisa é do tipo CPV-ARI e possui uma massa específica de $3,1 \mathrm{~g} / \mathrm{cm}^{3}$. Além disso, 
utilizou-se $0,4 \%$ de aditivo modificador de viscosidade (V-MAR ${ }^{\circledR}$ VSC500) em relação a massa de cimento.

A moldagem decorreu na seguinte ordem: primeiro todo o agregado graúdo foi colocado na betoneira, o qual encontrava-se na condição saturado superfície seca, seguido de parte da água, que objetiva aderir o aglomerante na superfície do agregado. Todo o aglomerante foi adicionado na sequência e posteriormente o restante da água juntamente com o aditivo. A consistência ideal do concreto permeável é obtida para um abatimento próximo de zero, de maneira prática, quando ao moldar uma "esfera" com a mão, ela permanece neste formato, sem que haja descolamento do agregado ou escoamento da pasta, como pode ser visualizado na Figura 4.

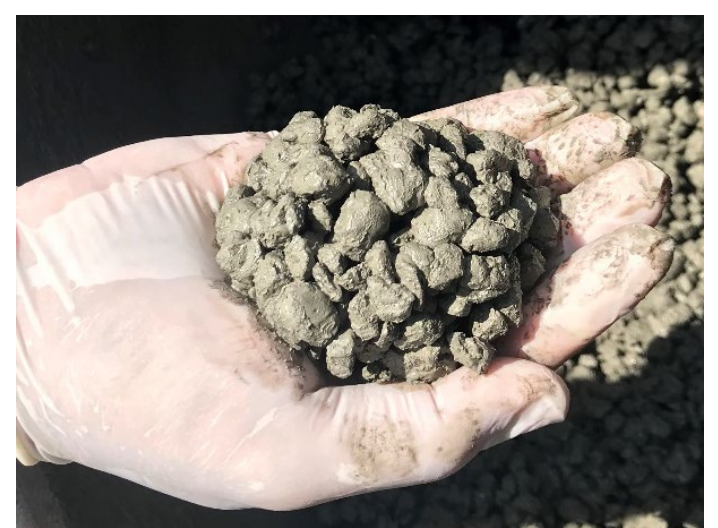

Figura 4. Abatimento próximo a zero, consistência ideal para moldagem do concreto permeável.

Os CP's cilíndricos de 10x20 cm foram compactados em duas camadas, com 20 golpes cada, já os CP's de 10x10 cm foram executados com apenas 1 camada com 20 golpes. Compactou-se com o Proctor, equipamento comumente utilizado em adensamento de solos. O uso do Proctor é recomendado pela ASTM subcommittee C09.49, desta forma é possível reduzir a dispersão nos resultados devido à diminuição do efeito de porosidade vertical (Martin III et al., 2014).

Para uma maior confiabilidade dos resultados, moldou-se 5 corpos de prova cilíndricos de dimensões 10x20 cm, para os ensaios de permeabilidade (NBR 14545 (ABNT, 2021)), porosidade (ASTM C1754: 2012) e resistência à compressão axial (NBR 5739 (ABNT, 2018); 3 corpos de prova cilíndricos de dimensões 10x10 cm, para o ensaio Cantabro (ASTM C1747: 2013); 5 corpos de prova prismáticos de dimensões $10 \times 10 \times 40 \mathrm{~cm}$, para o ensaio de resistência à tração na flexão (NBR 12142 (ABNT, 2010)). Os CP's prismáticos foram compactados com rolo de massa igual a $50 \mathrm{~kg}$, para uma melhor simulação da compactação em campo.

A porosidade (equação 1), assim como a permeabilidade, foram determinadas antes das amostras serem submetidas à ruptura. O permeâmetro de carga variável, construído na etapa 1 , foi utilizado para realizar o ensaio de permeabilidade. Ressalta-se que a norma utilizada é específica para solos, sendo feita uma simples adaptação. Neste ensaio, os CP's foram revestidos com uma membrana de látex, que impede o fluxo horizontal, e após a saturação, anotou-se o tempo necessário para a água percolar entre uma distância pré-estabelecida e assim, conforme a equação 2, o coeficiente de permeabilidade $(\mathrm{K})$ foi determinado através da Lei de Darcy.

$$
\begin{aligned}
& \mathrm{P}(\%)=\left[1-\left(\frac{M_{d}-M_{s}}{\rho_{w} \times V}\right)\right] \times 100 \\
& \mathrm{~K}\left(\frac{\mathrm{cm}}{\mathrm{s}}\right)=\frac{a \times L}{A x t} \times \log _{10}\left(\frac{h_{1}}{h_{2}}\right)
\end{aligned}
$$


O ensaio Cantabro consiste na medição da perda de massa de amostras submetidas à ação combinada de impacto e abrasão, através do contato entre as próprias amostras, sem o uso de esferas de aço, e o tambor rotativo, conhecido como máquina de abrasão Los Angeles. Após a realização dos ensaios de permeabilidade e porosidade, os CP's foram capeados com argamassa, este procedimento permite uma melhor área de contato entre o $\mathrm{CP}$ e a prensa, distribuindo, assim a carga uniformemente.

O ensaio de resistência à compressão, apesar de não ser uma variável limitante para pavimentos de concreto, proporciona informações relevantes quando está se analisando a influência dos agregados, já a resistência à tração na flexão, determinada pela equação 3 , fornece resultados importantes, sendo recomendado pela NBR 16416 (ABNT, 2015), visto que permite avaliar a viabilidade e aplicabilidade do pavimento. Os ensaios foram realizados aos 55 dias (porosidade, permeabilidade e abrasão) e aos 76 dias (mecânicos) ${ }^{1}$.

$$
f_{c t . f}=\frac{F \times l}{b \times d^{2}}
$$

\section{RESULTADOS E DISCUSSÕES}

A Figura 5 contém os dados da permeabilidade $v$. porosidade para os três tipos de agregados utilizados. Na Figura 5 (a) pode-se observar a distribuição para todos os corpos de prova, já na Figura 5 (b) é possível visualizar a média e o desvio padrão. Com isso, observa-se que, por meio da equivalência nos desvios-padrão, para o parâmetro permeabilidade (eixo y), os três agregados possuem funcionalidade hidráulica semelhante. Porém, quando se analisa a porosidade (eixo x), percebe-se que houve um ganho de porosidade para os agregados com índices de forma lamelar e lamelar-alongado.

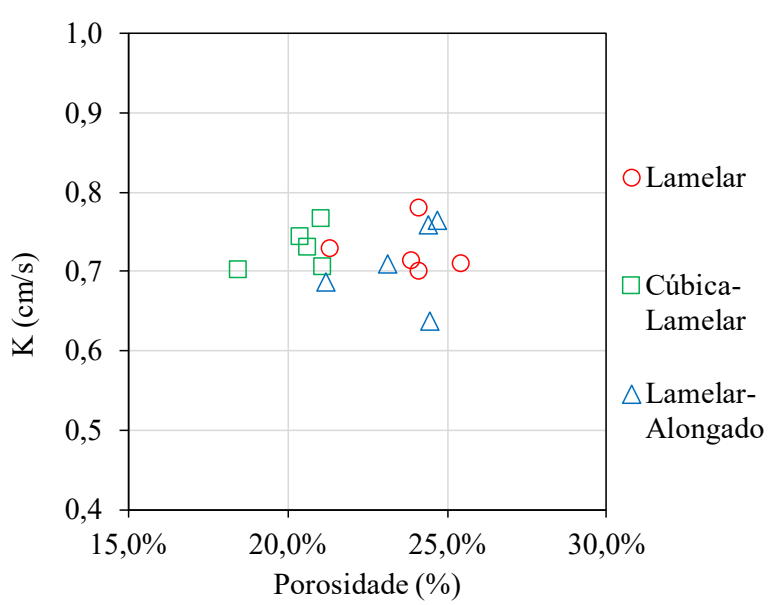

Figura 5. Permeabilidade vs. Porosidade: valores para todos os agregados (a) e valores médios

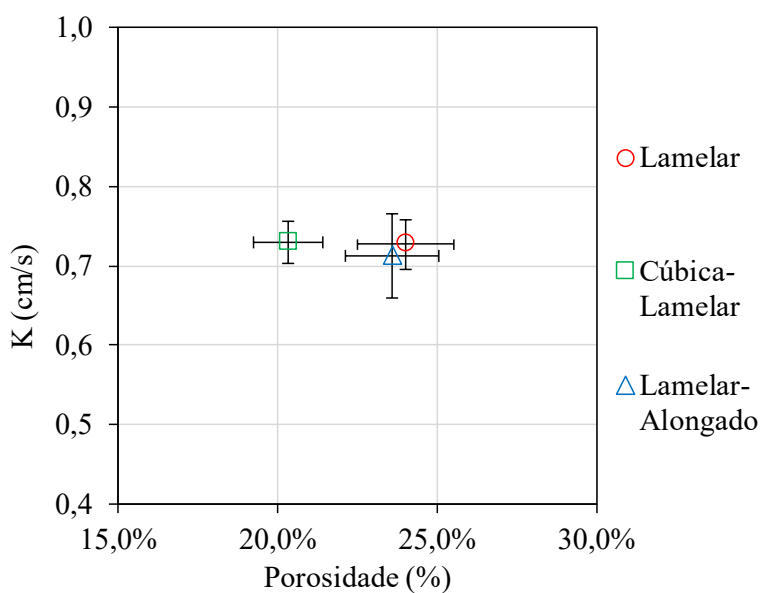

(b).

O fato de que a porosidade aumentou para os agregados com índice de forma lamelar e lamelaralongado, mas a permeabilidade permaneceu igual para os três tipos de agregados, pode ser explicado pela desconectividade ou tortuosidade dos poros, pois apesar de conter um maior número de vazios, a água pode ter difícil acesso a esses poros durante o escoamento, limitando a percolação de água. Este fato pode ser explicado pelo possível intertravamento de partículas mais lamelares e

\footnotetext{
${ }^{1}$ Datas possíveis de execução dos ensaios devido à pandemia pelo novo coronavírus que acarretou na interrupção das atividades acadêmicas e laboratoriais da Universidade no momento da execução desta pesquisa.
} 
alongados dos agregados deste fator de forma. Os valores médios para a permeabilidade encontram-se entre 0,7 e $0,8 \mathrm{~cm} / \mathrm{s}$, estando de acordo com os dados encontrados nos trabalhos de Montes e Halselbach (2006).

A Figura 6 apresenta os resultados da resistência à compressão, assim como anteriormente, estão divididos, onde na Figura 6 (a) estão todos os valores por amostra da resistência à compressão pela porosidade e na Figura 6 (b) estão os valores médios com o desvio-padrão.
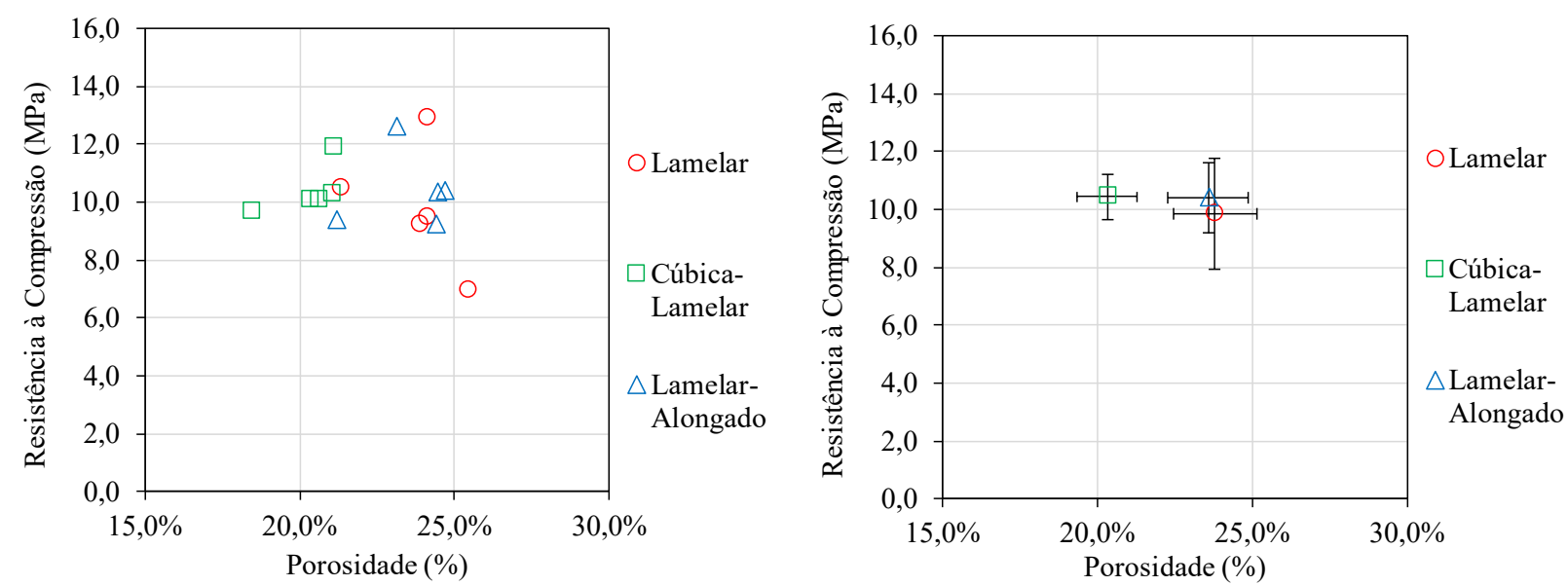

Figura 6. Resistência à compressão vs. Porosidade: valores para todos os agregados (a) e valores médios (b).

Ao analisar os gráficos é possível observar, a partir dos desvios-padrão, que não há diferença relevante entre os agregados para os valores de resistência à compressão (eixo y). Para a resistência em função da porosidade, percebe-se que o agregado cúbico-lamelar apresenta uma menor porosidade para um mesmo valor de resistência à compressão axial. Comumente, quanto maior o número de vazios menor a resistência mecânica (Batezini, 2013), no entanto, o que explica esta divergência é a possível presença de microfissuras internas no agregado cúbico-lamelar, que decorrem do processo de britagem, sendo utilizado para este agregado um britador terciário. Neste caso, o processo de britagem é fator determinante no desempenho mecânico do material.

Pressupõe-se, portanto que o fator de forma não influência na resistência à compressão, quando utilizado a mesma curva granulométrica e o mesmo traço. Os valores médios encontrados foram de aproximadamente $10 \mathrm{MPa}$ e estão próximos aos observados no trabalho de Costa et al. (2018) que avaliou em seu estudo um traço semelhante ao utilizado nessa pesquisa.

Na Figura 7, são apresentados os resultados referentes ao ensaio de resistência à tração na flexão. Uma vez que a porosidade foi medida apenas nos corpos de prova cilíndricos, o gráfico apresenta a média e o desvio-padrão para 5 (cinco) corpos de prova em função de cada tipo de agregado estudado. 


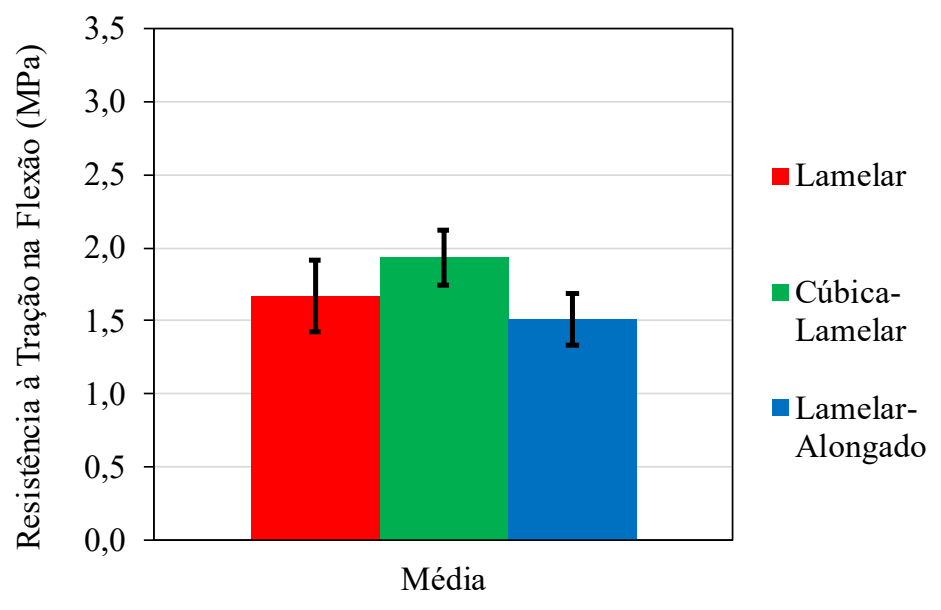

Figura 7. Valores médios para o ensaio de resistência à tração na flexão.

Ao observar o gráfico, percebe-se que ambas as amostras apresentaram uma resistência menor que a exigida pela NBR 16416 (ABNT, 2015), que estipula os requisitos e procedimentos para pavimentos de concreto permeável no Brasil. A resistência à tração na flexão mínima exigida pela norma é de 2,0 MPa, para um concreto permeável de trafego leve moldado in loco. A baixa resistência encontrada, pode ser explicada pela retirada do material passante na peneira 4,75 mm. Os materiais finos tendem a preencher os vazios e melhorar o intertravamento da mistura, elevando a resistência.

A partir da análise de variância realizada utilizando o método Anova de um único fator, a qual é apresentada na Tabela 1, pode-se afirmar que os agregados classificados como lamelar e cúbicalamelar, não diferem entre si quanto a resistência à tração, assim como a lamelar e a lamelaralongada, sendo estatisticamente diferentes, apenas os valores apresentados para agregado cúbicolamelar em relação ao agregado lamelar-alongado. Todavia, há uma tendência do agregado cúbicalamelar apresentar uma maior resistência, devido possivelmente ao fato que agregados cúbicos apresentam maior área de contato grão a grão envolvidos pela pasta e assim, maior capacidade de transferência de tensões. Enquanto, o agregado lamelar-alongado revela uma tendência a apresentar a menor resistência à tração na flexão, devendo-se a facilidade de quebra do agregado quando submetido a este tipo de esforço.

Tabela 1. Analise variância utilizando o método Anova de um único fator, com probabilidade de $95 \%$

\begin{tabular}{|c|c|c|c|}
\hline Descrição & Variância & Pvalor & Significativo \\
\hline Entre os grupos & 0,2281 & 0,0378 & Sim \\
\hline Lamelar - Cúbica lamelar & 0,5609 & 0,8053 & Não \\
\hline Cúbica lamelar - Lamelar alongada & 0,4486 & 0,0113 & Sim \\
\hline Lamelar - Lamelar alongada & 0,0674 & 0,3077 & Não \\
\hline
\end{tabular}

As imagens apresentadas na Figura 8, exemplificam o modo de ruptura dos CP's prismáticos ensaiados nesta pesquisa. Observa-se na Figura 8 (a) a formação de uma única fissura, localizada próxima ao centro do vão que percorre a maior parte da seção transversal. A fissura ocorreu no contorno dos grãos na região de maior solicitação. Pressupõe-se que esta fissura ocorreu na zona transição entre o agregado e a pasta, devido a fragilidade da ligação, porém ao analisar a Figura 8 
(b) nota-se que houve também a quebra dos agregados, evidenciando a transferência de esforços solicitantes.
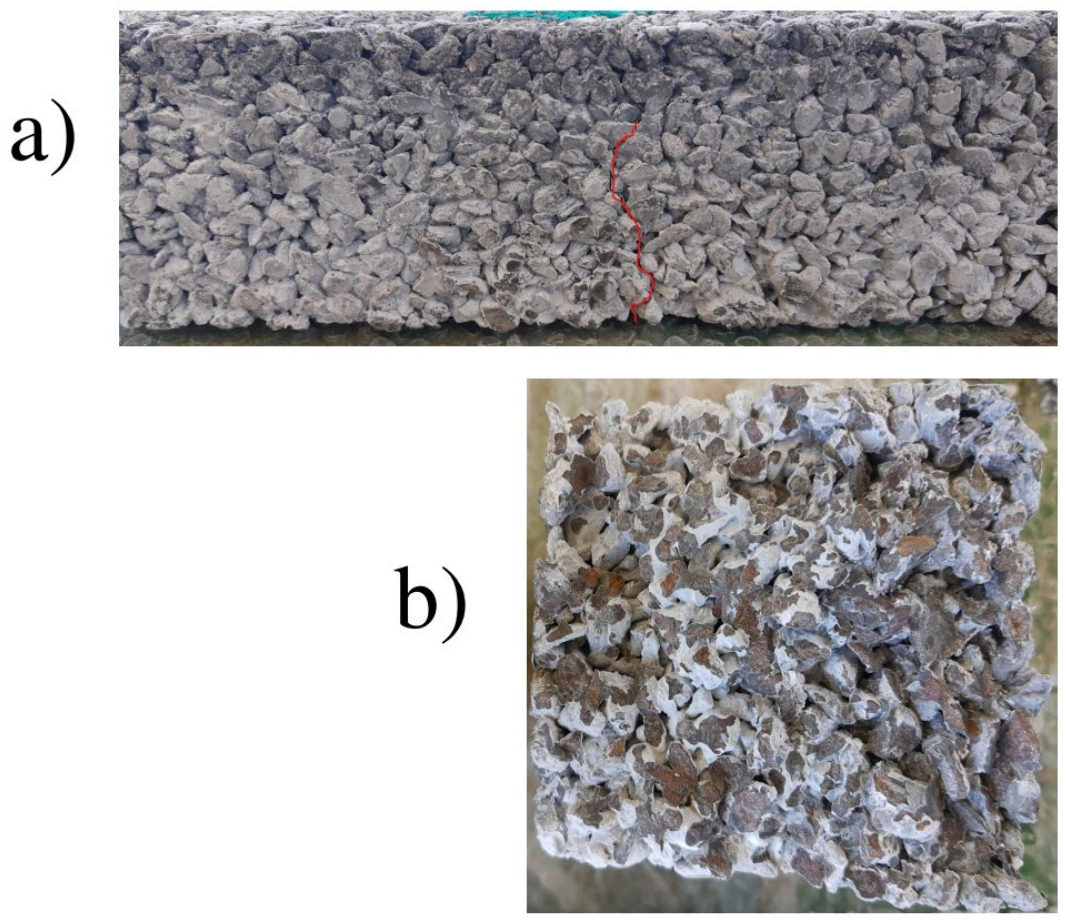

Figura 8. Modo de ruptura de um CP prismático submetido à esforços de tração na flexão.

A Figura 9 apresenta a perda de massa por meio do ensaio Cantabro, no qual obteve-se a perda de massa de três CP's cilíndros de dimensões $10 \times 10 \mathrm{~cm}$, a cada 100 rotações até um total de 500 rotações. Vale ressaltar que foi utilizado a média das perdas de massas, devido à dificuldade de identificação dos CP's no transcorrer do ensaio.

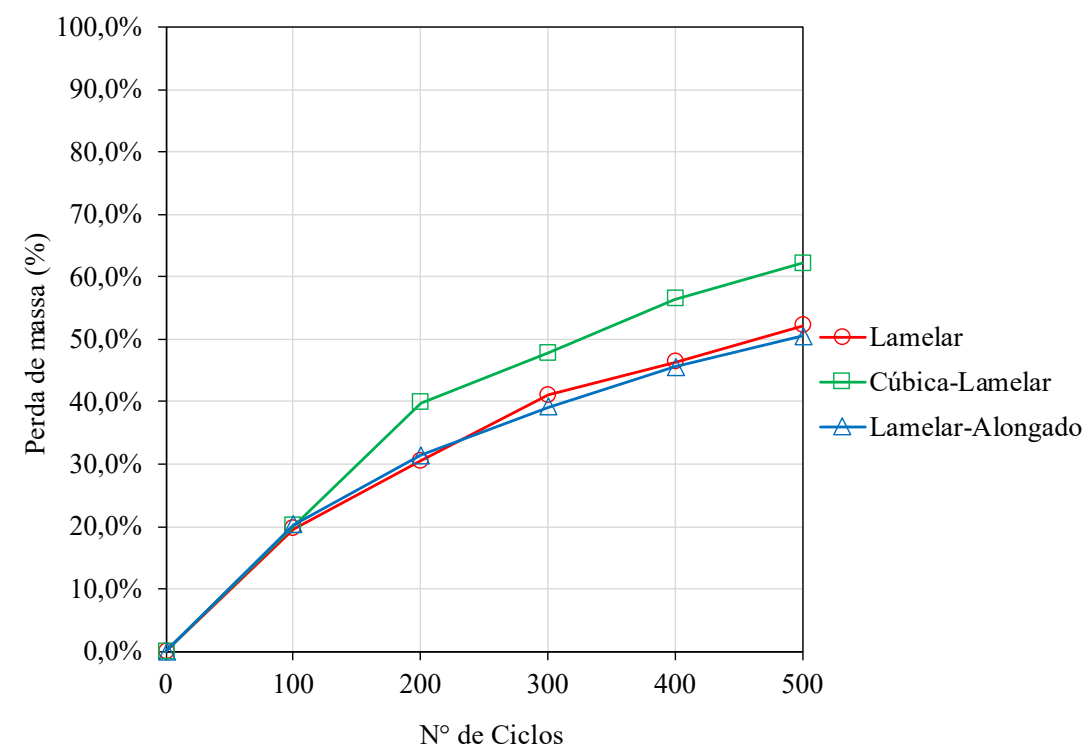

Figura 9. Perda de massa em função do número de ciclos realizados no ensaio de cântabro.

Como pode-se visualizar na Figura 9, o agregado de forma cúbica-lamelar apresentou uma perda de massa, aproximadamente, 10\% maior comparado aos outros dois agregados. Essa maior perda 
de massa pode ser devido ao processo de britagem que, como citado anteriormente, proporciona possíveis microfissuras internas, diminuindo a resistência à abrasão.

\section{CONCLUSÕES}

Os agregados graúdos influenciam o comportamento do concreto permeável, frente a formação dos poros interconectados, pelos quais a água percola no pavimento. No entanto, quando analisado o índice de forma dos agregados, estes não evidenciaram diferenças expressivas no potencial hidráulico e na capacidade mecânica. $\mathrm{O}$ fato de a resistência mecânica não ter sido alterada quando comparado os dois extremos no formato dos agregados, cúbico-lamelar e lamelar-alongado, decorre possivelmente do processo de britagem dos agregados. O agregado cúbico-lamelar é obtido por um britador de impacto, o qual pode causar, devido aos processos de britagem, microfissuras no interior do agregado e reduzir sua resistência. Por outro lado, o agregado lamelar-alongado é adquirido por um britador cônico, que proporciona menos esforços solicitantes ao agregado. Nesse sentido, as seguintes conclusões podem ser observadas:

- Os agregados classificados em lamelar, lamelar-alongado e cúbica-lamelar conferiram características hidráulicas semelhantes ao concreto permeável;

- Quando comparados em relação a resistência à compressão em função da porosidade, os agregados lamelar e lamelar-alongado são equivalentes, já o agregado cúbico-lamelar apresenta uma resistência semelhante aos demais, porém com uma porosidade de aproximadamente $4 \%$ a menos;

- Na resistência a tração na flexão, os resultados revelam uma tendência de superioridade para a cúbica-lamelar quando comparada a lamelar-alongada, enquanto os demais agregados não apresentam diferenças estatísticas;

- O agregado cúbico-lamelar apresentou a maior perda de massa no ensaio Cantabro, com aproximadamente $10 \%$ a mais de perda que os outros agregados, devido a fragilidade do agregado.

\section{AGRADECIMIENTOS}

Os autores agradecem ao Programa de Desenvolvimento Acadêmico (PDA) da Universidade Federal do Pampa, pela bolsa de pesquisa, e a Brita Pinhal Indústria e Comércio Ltda, localizada no município de Itaara - RS, pela doação do agregado cúbico-lamelar.

\section{REFERENCIAS}

Associação Brasileira de Normas Técnicas. (2005). ABNT NBR 53: Agregado graúdo Determinação da massa específica, massa específica aparente e absorção de água-Método de ensaio. Rio de Janeiro.

Associação Brasileira de Normas Técnicas. (2003). ABNT NBR 248: Agregados - Determinação da composição granulométrica - Método de ensaio. Rio de Janeiro.

Associação Brasileira de Normas Técnicas. (2021). ABNT NBR 14545: Solo - Determinação do coeficiente de permeabilidade de solos argilosos à carga variável. Rio de Janeiro.

Associação Brasileira de Normas Técnicas. (2018). ABNT NBR 5739: Concreto - Ensaio de compressão de corpos de prova cilíndricos. Rio de Janeiro. 
Associação Brasileira de Normas Técnicas. (2019). ABNT NBR 7809: Agregado graúdo Determinação do índice de forma pelo método do paquímetro - Método de ensaio. Rio de Janeiro.

Associação Brasileira de Normas Técnicas. (2010). ABNT NBR 12142: Concreto - Determinação da resistência à tração na flexão de corpos de prova prismáticos. Rio de Janeiro.

Associação Brasileira de Normas Técnicas. (2015). ABNT NBR 16416: Pavimentos permeáveis de concreto - Requisitos e procedimentos. Rio de Janeiro.

American Society for Testing and Materials. (2012). ASTM C1754/C1754M: Standard Test Method for Density and Void Content of Hardened Pervious Concrete. West Conshohocken, PA, United States of America.

American Society for Testing and Materials. (2013). ASTM C1747/C1747M: Standard Test Method for Determining Potential Resistance to Degradation of Pervious Concrete by Impact and Abrasion. West Conshohocken, PA, United States of America.

U.S. ENVIRONMENTAL PROTECTION AGENCY (EPA). Urbanization and streams: studies of hydrological impacts. Office of Water. Publicação 841-R-97-009. Washington D.C., 1997.

Batezini, R. (2013). Estudo preliminar de concretos permeáveis como revestimento de pavimentos para áreas de veículos leves. Dissertação de Mestrado, Universidade de São Paulo, São Paulo.

Boaretto, G. O. F. (2017). Estudo comparativo da substituição gradativa de agregado graúdo na forma lamelar pela forma cúbica nas propriedades do concreto. Trabalho de Conclusão de Curso, Universidade Federal de Santa Catarina, Joinville.

Costa, F. B. P.; Lorenzi, A.; Haselbach, L.; Silva Filho, L. C. P. Best practices for pervious concrete mix design and laboratory tests in Revista IBRACON de Estruturas e Materiais, v.11, n.05, pp. 1151-1159. https://doi.org/10.1590/S1983-41952018000500013

Figueira, H. V. O., Luz, A. B., Almeida, S. L. M. (2010), “ Comunicação Técnica elaborada para o Livro Tratamento de Minérios" 5 Edição - Capítulo 4 - pág. 143-211.

Martin III, W. D.; Kaye, N. B.; Putman, B. J. (2014). Impact of vertical porosity distribution on the permeability of pervious concrete in Construction and Building Materials, v.59, p. 78-84.

https://doi.org/10.1016/j.conbuildmat.2014.02.034

Montes, F.; Haselbach, L. (2006). Measuring hydraulic conductivity in pervious concrete in Environmental Engineering Science, v.23, n.6, p. 960-969.

https://doi.org/10.1089/ees.2006.23.960

Pereira Da Costa, F. B. P. (2019). Análise e Desenvolvimento de Misturas de Concreto Permeável para Aplicação em Pavimentação. Tese de Doutorado, Universidade Federal do Rio Grande do Sul, Porto Alegre. 
Silva, D. A. Geyer, A. L. B. (2018). Influência da Forma do agregado graúdo nas propriedades mecânicas do concreto in Revista Científica Multidisciplinar Núcleo do Conhecimento. Ano 03, Ed. 12, Vol. 05, pp. 67-82.

Influência da Forma do agregado graúdo nas propriedades (nucleodoconhecimento.com.br)

Singh, A., Sampath, P. V., \& Biligiri, K. P. (2020). A review of sustainable pervious concrete systems: Emphasis on clogging, material characterization, and environmental aspects. Construction and Building Materials, 261, 120491. doi:10.1016/j.conbuildmat.2020.120491

VALENÇA, Guilherme Sanguinetti et al. Análise da viabilidade do uso do concreto permeável na utilização de pavimento leve em vias urbanas. Brazilian Journal of Development, v. 7, n. 3, p. 28803-28816, 2021. 